\title{
Prader Willi Syndrome in Pediatric Patients: Nutritional Education to Prevent Obesity
}

\author{
Rosanio FM, Casertano A, Cuccurullo I, Occhiati L, Malvone FP, Mozzillo E and \\ Franzese $A^{*}$ \\ Department of Translational Medical Sciences, Section of Pediatrics, Italy

\begin{abstract}
Prader Willi syndrome is the most common cause of syndromic obesity. Obesity and its complications are the major causes of morbidity and mortality. It is crucial to prevent the onset of obesity since, once it has arisen, it is difficult to maintain the control of food intake. Unfortunately, preventing obesity in PWS patients still remains a difficult goal to achieve and requires constant supervision of the caregivers through behavioral interventions implemented from the earliest stages of life, when the PWS patient has not yet expressed compulsive eating-related traits. Aim of this paper is to focus on the different experiences and recommendations on dietary approach in literature, including that of our Center. Early diagnosis and nutritional treatment, an accurate follow-up, but also the social background, are important elements in the patient future management.
\end{abstract}

ISSN: 2578-0263

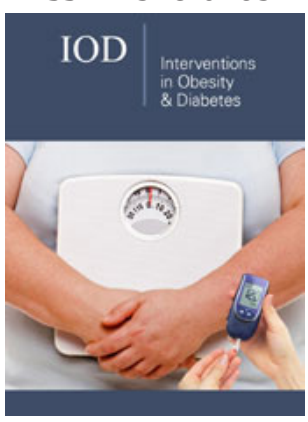

*Corresponding author: Adriana Franzese, Department of Translational Medical Sciences, Section of Pediatrics, Federico II University, Naples, Italy

Submission: 梅 September 30, 2020

Published: 制 December 22, 2020

Volume 4 - Issue 4

How to cite this article: Rosanio FM Casertano A, Cuccurullo I, Occhiati L, Malvone FP, Mozzillo E and Franzese A. Prader Willi Syndrome in Pediatric Patients: Nutritional Education to Prevent Obesity. Interventions Obes Diabetes 4(4) IOD.000594. 2020.

DOI: 10.31031/IOD.2020.04.000594

Copyright@ Adriana Franzese. This article is distributed under the terms of the Creative Commons Attribution 4.0 International License, which permits unrestricted use and redistribution provided that the original author and source are credited.
Keywords: Prader Willi syndrome; Obesity; Diagnosis; Body weight; Nutritional

\section{Introduction}

Prader Willi syndrome (PWS) is a neuro-developmental genetic disorder due to loss of paternally genes in chromosome 15 (15q11.2-q-13 region). This syndrome is the most common cause of syndromic obesity, occurring in 1:10.000-25.000 live births. The loss of function can be due to a deletion (70\% of the cases), to a maternal uniparental disomy (UDP, $20-30 \%$ of cases), to an imprinting defect (1-3\% of the cases) or to an unbalanced translocation (1\%) [1]. The clinical picture of PWS is extremely broad and includes short stature, multiple endocrine abnormalities (hypogonadism, growth hormone/insulin-like growth factor 1 axis dysfunction, hypothyroidism, central adrenal insufficiency), dysmorphic features (dolichocephaly, narrow minimal frontal diameter, strabismus, almond-shaped eyes, short upturned nose, thin upper lip, down-turned corners of the mouth, sticky salvia, dry mouth with enamel hypoplasia, small hands and feet), genital abnormalities (small penis and cryptorchidism in male; absent labra minora in female), hypopigmentation, scoliosis, osteoporosis [2]. In first months of life, the main features of PWS include low birth weight, hypotonia and feeding difficulties resulting in failure to thrive (FTT); hyperphagia and weight gain appear later, sometimes even in the second semester of life, generally in the second year, leading to severe obesity. Over time, cognitive impairment, behavioral problems (temper tantrums, stubbornness, outbursts, selfinjury) and psychiatric illness (obsessive compulsive disorder, schizophrenia, autism) also become evident during the years.

Obesity and its complications are the major causes of morbidity and mortality in PWS patients and badly affects mental and psychomotor performance. It is crucial to prevent the onset of obesity since, once it has arisen, it is difficult to maintain the control of food intake [3]. Furthermore, prognosis of PWS is significantly worsened by obesity-related complications that include right heart dysfunction, metabolic syndrome, arterial hypertension, steatohepatitis, gallstones, deep venous thromboses, glucose metabolism disorders, hyperlipidemia, respiratory problems and sleep disorders [4]. Over the past two decades, earlier diagnosis and GH-therapy have greatly increased the possibilities for clinical improvement of PWS patients both in childhood and in adulthood, but weight control remains the first and main therapeutic strategy to prevent obesity-related complications. Aim of this paper is to focus on the different experiences and recommendation on dietary approach in literature and to include that of our Center. 


\section{Nutritional Strategies in the Literature}

Obesity is the result of an imbalance between energy intake, due to an insatiable sense of hunger, and expenditure, due to hypothalamic and hormonal defects. This imbalance between spending and energy intake is worsened by reduced physical activity common in young PWS patients. The spasmodic search for food can lead them to search for food from the garbage and to lie to caregivers on the quantities of food consumed. Moreover, due to the reduced lean mass, low physical activity and reduced basal energy expenditure, PWS subjects gain weight even if they take the calories recommended for subjects for age. Two distinct nutritional stages in PWS have been described: the first stage, in early infancy, characterized by poor feeding and hypotonia, often associated with FTT; the second stage, in early childhood, dominated by hyperphagia leading to obesity. Miller et al. described a more complex and gradual progression of the nutritional phases in PWS identifying a total of seven different nutritional phases, starting from before birth (phase 0) and continuing into childhood (phase $1 \mathrm{a}, 1 \mathrm{~b}, 2 \mathrm{a}, 2 \mathrm{~b}$ and 3 ) and adult life (phase 4) [5]. In (Table 1) are synthetized the main recommendation collected from literature with the following characteristics: papers exclusively focused on nutritional management in PWS pediatric population and published in recent 15 years. As is clear from the experiences of literature, the more common strategy is a $20-40 \%$ reduction of the recommended daily allowance in PWS children compared to healthy age-matched children. It is essential that this dietary restriction starts early, immediately after the recovery of birth weight and before the nutritional phase 2. Since it is difficult to obtain a significant weight loss in an already obese PWS patient, it is absolutely essential to prevent the onset of obesity from the first months of life. As demonstrated by Miller et al., adherence to a specific energy restricted diet reduces the proportion of body fat and BMI in PWS children and adults [6]. This suggests that hyperphagia and subsequent obesity are not inevitable, but they could be prevented by tailored restriction of caloric intake. Underlying the appetite dysregulation is the suppression of the anti-aging Sirt- 1 gene and many other genes that are linked to programmed cell death and dysregulation of metabolism. Nutritional therapy includes not only low-calorie diets but also healthy foods that do not contain LPS, mycotoxins or xenobiotics, substances able to suppress the activity of Sirt1 [7].

Table 1: Dietary guidelines and recommendations from literature in PWS pediatric patients. CHO: carbohydrates.

\begin{tabular}{|c|c|c|}
\hline Authors & Caloric Intake & Diet \\
\hline Chen [6] & $\begin{array}{l}800-900 \mathrm{kcal} / \text { day in toddlers; later } 1000- \\
1200 \mathrm{kcal} / \text { day. }\end{array}$ & Balanced with addition of micronutrients \\
\hline Schmidt [7] & $10 \mathrm{kcal} / \mathrm{cm}$ height & $\begin{array}{l}25 \% \text { proteins, } 20 \% \text { fat, } 55 \% \text { modified CHO, sugars } \\
\text { reduced. } 3 \text { meals and } 3 \text { snacks. }\end{array}$ \\
\hline Bonfig [8] & $10 \mathrm{kcal} / \mathrm{cm}$ height & $\begin{array}{l}25 \% \text { proteins; } 20 \% \text { fat, } 55 \% \text { CHO, sugars reduced. } \\
\text { Supply of micronutrients. Fat-free or very low-fat diet. } \\
3 \text { meals and } 3 \text { snacks. }\end{array}$ \\
\hline Goldstone [9] & Early institution of a low-calorie diet & Balanced \\
\hline Pereira [10] & 11 calories/cm to maintain, 8-9 to lose weight. & Nutrient-dense foods with addition of vitamins. \\
\hline Yearwood [11] & Not specified & $\begin{array}{l}\text { High fiber foods, } \mathrm{CHO} \text { with low Glycemic index. Chose } \\
\text { lean meats, eggs, and poultry as proteins. Hypocaloric } \\
\text { snacks. }\end{array}$ \\
\hline Miller [12] & 7-11kcal kg & $\begin{array}{l}10-23 \% \text { fat, } 15-20 \% \text { proteins, } 50-70 \% \text { CHO, } 12 \mathrm{~g} \text { fiber } / \\
\text { day }\end{array}$ \\
\hline Lima [13] & $14 \mathrm{kcal} / \mathrm{cm} /$ day to maintain; 7 if lose weight & No fat and sugar. Portions individualized \\
\hline Passone [14] & Start with a $900 \mathrm{kcal} /$ day diet & $\begin{array}{l}\text { Small portions: vegetables 6-8/day; CHO 3-5; fruit 4; } \\
\text { milk and dairy products 2; meat 1-2; fat and sweets } \\
\text { sporadically. Addition of micronutrients. Ketogenic diet } \\
\text { to lose weight. }\end{array}$ \\
\hline Duis [15] & Calorie restriction & $\begin{array}{l}\text { Higher fat/lower CHO diet. NO sugars and sweeteners. } \\
\text { Drinking water. Proteins at every meal, fiber 20g. Addi- } \\
\text { tion of CoQ10, Carnitine, MCT oil, vitamins, DHA }\end{array}$ \\
\hline Crinò [16] & $60 \%-80 \%$ recommended daily allowance/age & $\begin{array}{l}\text { Healthy foods, vegetables/fruits. Encourage to drink } \\
\text { water. Smaller food portions. No food restricted treats } \\
\text { as a form of punishment. }\end{array}$ \\
\hline
\end{tabular}


The poor physical activity in PWS patients is due to their peculiar characteristics in terms of body composition (reduced lean mass) and muscle tone (hypotonia, reduced muscle strength) which lead these patients to avoid physical exercise. Only $12 \%$ of PWS patients reach the recommended hours of daily physical activity compared to the normal population BMI-matched [8]. Behavioral interventions aimed at increasing the level of physical activity in PWS improve lean mass, resistance to physical work and spontaneous physical activity [9]. Behavioral-psychiatric problems tend to worsen with age by increasing obesity and reducing physical activity due to social isolation. Often these patients have altered circadian rhythms, suffer from sleep apnea and excessive daytime sleepiness [10].

\section{Experience of our Center}

Alongside the experience of literature presented above, we report our experience over the last two decades. Management is handled by a team composed of a doctor, psychologist (or neuropsychiatrist) and nutritionist, it is activated as soon as the diagnosis arrives, even if only suspicious, and is structured as follows:

\section{Patient with early diagnosis}

a. Program presentation: In case of diagnosis in the first weeks of life, when patient may still be under-weight, we usually present to parents the entire management path in terms of strong risk of future obesity, showing as better as possible that good work on the child will be rewarded by major improvements in all physical and mental performances. It should be explained to parents that the child should not be accustomed to food-related gratifications and that meals must be well regulated in term of times, food sequence and absence of TV and therefore rules of nutrition and education as showed in (Table 2).

b. Calories restriction: A concrete calories restriction is proponed when the little child has reached the normal curve in weight percentiles: in fact, considering the child's hypotonia and less physical activity we think reasonable to reduce of $20-25 \%$ the normal energy income for age.

c. Follow up: In the successive follow up body weight should be controlled by staying in the same percentile channel. To verify and encourage the maintenance of a normal weight, we instituted a follow-up initially quarterly and then every six months.

\section{Patient with tardive diagnosis}

In case of tardive diagnosis, especially when the child is already obese, we present to parents the complete picture of present and future complications and we perform all possible strategies to achieve weight loss, trying to change the child's bulimic and obsessive behaviors and encouraging physical activity in every way. Also in this case the recommendations are those presented in (Table 2).

Table 2: Synthetized some behavioral advices [modified from Crinò et al. [22]].

\begin{tabular}{|r|}
\hline Education-Behavioral Advice \\
\hline 1. Environmental modifications: locking the kitchen, cupboards, and refrigerator [even garbage]. \\
\hline 2. Meals should fall at the same time each day creating illusion of abundance using small plates and cutting food into smaller pieces. \\
\hline 3. Choose healthy and low-calorie snacks. \\
\hline 4. Incite to physical exercise and create a daily program to keep the patient occupied which includes all activities, exercise, meals, and breaks. \\
\hline 5. Approve and laud all good behavior with instant rewards using recompenses other than food; no food restricted treats as a form of punishment. \\
\hline
\end{tabular}

\section{Patients and follow up of the body weight}

Twenty-one PWS patients (13 male, mean age 9,3 years) are currently in follow-up at Federico II University of Naples. We stratified our population of PWS patients based on age at the time of first access to our center (distinguishing those with early diagnosis within the first year of life from those with late diagnosis after the first year of life). Collected data were: BMIzscore at present (with standard deviation score (SDS) based upon the Italian BMI normative curves), number of school-years of both parents (Level 1:<8 years; 2: 8-13 years; 3:>13 years) and family income (Level 1:<15.000 euro/year; 2:15-30000 euro/ year; 3:>30000 euro/year). Twelve patients ( 6 male, mean age 6,3 years) received an early diagnosis (mean 2 months). To date, after a mean follow up duration of 5,6 years, 4/12 have a severe obesity degree (BMIz-score>+2DS) while the remaining 8 patients (67\%) maintained an adequate weight (BMIz-score between +2 and -2). Conversely, among 9 patients who received a late diagnosis (mean age at diagnosis 4,4 years), to date 7 patients have a BMIz-score>+2DS; one of these, recently affected by Type 2 diabetes, died of respiratory failure at 11 years; another underwent bariatric surgery at 14 years with partial weight recovery successively [11]. All 8 children of high level of education of parents and high level of family income have BMIz-score between +2 and -2 ; of these, 6 were early diagnoses and 2 were late diagnoses. Although most PWS patients show mild to moderate intellectual disability, rare PWS patients with high social background who present a good cognitive performance are described in the literature [12]. 


\section{Discussion and Conclusive Remarks}

Obesity is the leading cause of morbidity and mortality in PWS and weight control is the most important purpose of any PWS treatment program. The mechanism underlying obesity in PWS patients has not yet been elucidated but it would seem to be due to three fundamental mechanisms: alteration of hypothalamic circuits that regulate satiety, low physical activity and altered feeding behavior. Energy-restricted diet with a well-balanced macronutrient composition and fiber intake improves both weight and body composition in PWS children compared to a simple energy-restricted diet. Not adequate intake of calories, calcium and vit D leads to impaired growth: in Schmidt's study a fat-reduced and carbohydrate modified diet providing $10 \mathrm{kcal} / \mathrm{cm}(42 \mathrm{~kJ} / \mathrm{cm}$ of height) starting at the second year of life, resulted in shorter stature when compared with a control group of PWS diagnosed at a later stage in life [13]. This suggests the consideration of adequate nutritional support tailored to individuals and not just an indiscriminate energy restriction. Managing an already obese PWS patient is extremely difficult and, since there are no proven drugs for the treatment of hyperphagia, the only acceptable strategy is to prevent the onset of obesity. Unfortunately, prevent obesity in PWS patient still remains a difficult goal to achieve and requires constant supervision of the caregivers through behavioral interventions implemented from the earliest stages of life, when the PWS patient has not yet expressed compulsive eating-related traits [14-20].

In our experience, the early diagnosis of the syndrome, when the newborn is floppy and often dystrophic, is a key moment in the patient future management. It is at this stage that parents must be informed about the risks associated with hyperphagia, providing them all the tools to avoid excessive uncontrolled weight gain. A psychological and behavioral counseling is recommended. Not only a strict dietary regime, but even physical activity is essential to avoid excessive weight gain $[21,22]$. It is important to include the patient in an occupational therapy program to distract him from the continuous search for food. When the syndrome is diagnosed late, often patient is already obese and lifestyle interventions are often ineffective. Especially for these patients, the possibility of discovering a drug to control hyperphagia represents the main challenge for the future. Since at the moment there are no effective drugs for weight control, bariatric surgery may represent an alternative in severe obese patients with comorbidities. Unfortunately, PWS patients have intellectual disability and psychiatric issues that are traditionally a contraindication to bariatric surgery, although, in exceptional cases, it is still necessary to use it [11]. In the literature there is no methodical evaluation of the obesity risk by social level and by educational level of the parents, while it is widely referred that early diagnosis and systematic follow-up are essential to control the patient's excess weight. Multicenter studies with large case series are needed to better clarify the relationship of obesity risk with early diagnosis and accurate follow-up, but also the social level and the years of parental studies. The best knowledge of these risk factors could be useful to set the treatment in an adequate way and modeled on the needs and characteristics of each family of a child with PWS.

\section{Authors' Contribution}

R.F.M. and C.A. wrote the review, M.F.P., I.C. and O.L. collaborated to literature and practical management, M.E. and F.A. reviewed the paper, F.A. created the idea and supervised.

\section{References}

1. Cassidy SB, Schwartz S, Miller JL, Driscoll DJ (2012) Prader-Willi syndrome. Genetic Medicine 14: 10-26.

2. Gunay Aygun M, Schwartz S, Heeger S, O Riordan MA, Cassidy SB (2001) The changing purpose of Prader-Willi syndrome clinical diagnostic criteria and proposed revised criteria. Pediatrics 108(5): E92.

3. Khan MJ, Gerasimidis K, Edwards CA, Shaikh MG (2018) Mechanisms of obesity in Prader-Willi syndrome. Pediatr Obes 13(1): 3-13.

4. Canora A, Franzese A, Mozzillo E, Fattorusso V, Bocchino M, et al. (2018) Severe obstructive sleep disorders in Prader-Willi syndrome patients in southern Italy. Eur J Pediatr 177(9): 1367-1370.

5. Miller JL, Lynn CH, Driscoll DC, Goldstone AP, Gold AJ, et al. (2011) Nutritional phases in Prader-Willi syndrome. Am J Med Genet A 155(5): 1040-1049.

6. Miller JL, Lynn CH, Shuster J, Driscoll DJ (2013) A reduced-energy intake, well-balanced diet improves weight control in children with PraderWilli syndrome. J Hum Nutr Diet 26(1): 2-9.

7. Martins IJ (2016) Anti-aging genes improve appetite regulation and reverse cell senescence and apoptosis in global populations. Advances in Aging Research 5(1): 9-26.

8. Eiholzer U, Nordmann Y, Allemand D, Schlumpf M, Schmid S, et al. (2003) Improving body composition and physical activity in Prader-Willi syndrome. J Pediatr 142: 73-78.

9. Lindmark M, Trygg K, Giltvedt K, Kolset SO (2010) Nutrient intake of young children with Prader-Willi syndrome. Food Nutr Res 54: 10.

10. Rubin DA, Nowak J, McLaren E, Patiño M, Castner DM, et al. (2015) Nutritional intakes in children with Prader-Willi syndrome and noncongenital obesity. Food Nutr Res 59: 29427.

11. Tripodi M, Casertano A, Peluso M, Musella M, Berardi G, et al. (2020) Prader-Willi Syndrome: Role of bariatric surgery in two adolescents with obesity. Obes Surg 30(11): 4602-4604.

12. Nugnes R, Zito E, Mozzillo E, Camarca ME, Riccio MP, et al. (2013) Good cognitive performances in a child with Prader-Willi syndrome. Ital J Pediatr 39: 74.

13. Schmidt H, Pozza SB, Bonfig W, Schwarz HP, Dokoupil K (2008) Successful early dietary intervention avoids obesity in patients with Prader-Willi syndrome: A ten-year follow-up. J Pediatr Endocrinol Metab 21(7): 651655.

14. Chen C, Visootsak J, Dills S, Graham JM (2007) Prader-Willi syndrome: An update and review for the primary pediatrician. Clin Pediatr (Phila) 46(7): 580-591.

15. Bonfig W, Dokoupil K, Schmidt H (2009) A special, strict, fat-reduced, and carbohydrate-modified diet leads to marked weight reduction even in overweight adolescents with Prader-Willi syndrome (PWS). Scientific World Journal. 9: 934-939.

16. Goldstone AP, Holland AJ, Hauffa BP, Hokken Koelega AC, Tauber M (2008) Recommendations for the diagnosis and management of PraderWilli syndrome. J Clin Endocrinol Metab 93(11): 4183-4197. 
17. Pereira R, Schalk A, Geraghty ME (2009) Prader-Willi Syndrome: A Review for pediatric nutrition professionals. Infant Child \& Adolescent Nutrition.

18. Yearwood EL, McCulloch MR, Tucker ML, Riley JB (2011) Care of the patient with Prader-Willi syndrome. Medsurg Nurs 20(3): 113-122.

19. Lima VP , Emerich DR, Mesquita ML, Paternez AC, Carreiro LR, et al. (2016) Nutritional intervention with hypocaloric diet for weight control in children and adolescents with Prader-Willi Syndrome. Eat Behav 21: 189-192.
20. Passone CBG, Pasqualucci PL, Franco RR, Ito SS, Mattar LBF, et al. (2018) Prader-Willi Syndrome: What is the general pediatrician supposed to do?-A review. Rev Paul Pediatr 36(3): 345-352.

21. Duis J, van Wattum PJ, Scheimann A, Salehi P, Brokamp E, et al. (2019) A multidisciplinary approach to the clinical management of Prader-Willi syndrome. Mol Genet Genomic Med 7(3): e514.

22. Crinò A, Fintini D, Bocchini S, Grugni G (2018) Obesity management in Prader-Willi syndrome: Current perspectives. Diabetes Metab Syndr Obes 11: 579-593. 